Gut, 1988, 29, 669-674

\title{
Clinical trials
}

\section{Comparison of delayed release 5 aminosalicylic acid (mesalazine) and sulphasalazine in the treatment of mild to moderate ulcerative colitis relapse}

\author{
S A RILEY, V MANI, M J GOODMAN, M E HERD, S DUTT, \\ AND L A TURNBERG \\ From the Department of Medicine, University of Manchester Medical School, Hope Hospital, Salford and \\ Leigh Infirmary and the Departments of Medicine and Histopathology, Bury General Hospital, Manchester
}

SUMMARY Oral formulations of 5-aminosalicylic acid (mesalazine) appear less toxic than sulphasalazine. We have therefore compared sulphasalazine, low dose mesalazine and high dose mesalazine in the treatment of mild to moderate relapse of ulcerative colitis. Sixty one patients (32 men, aged 20-78 years) were randomly allocated to sulphasalazine $2 \mathrm{~g}$ daily, mesalazine $800 \mathrm{mg}$ daily, or mesalazine $2.4 \mathrm{~g}$ daily in a double blind, double dummy, four week trial. Groups were comparable for age, sex, extent of disease, and pretrial sulphasalazine intake. Four patients were unable to complete the study because of treatment failure (two taking sulphasalazine and two high dose mesalazine). A further two patients taking sulphasalazine developed side effects necessitating withdrawal. Within treatment comparisons revealed significant improvement of: sigmoidoscopic grade in the sulphasalazine group; rectal bleeding, sigmoidoscopic and histological grade in the low dose mesalazine group; stool frequency, rectal bleeding and sigmoidoscopic grade in the high dose mesalazine group. Greater improvement in rectal bleeding $(\mathbf{p}<0.05)$ and sigmoidoscopic appearances $(p<0 \cdot 05)$ occurred in patients taking high dose mesalazine than in those taking sulphasalazine. In two patients taking high dose mesalazine minor rises of plasma creatinine concentrations occurred, suggesting the need to monitor renal function.

Although the main value of sulphasalazine (SSZ) is in the maintenance of ulcerative colitis remission ${ }^{1-3}$ it is also of benefit in active disease. ${ }^{\text {to }}$ Many patients, however, are unable to take the drug as side effects are common, particularly at high doses.' As most of these side effects are similar to those seen with sulphonamide drugs and as they correlate well with plasma sulphapyridine concentrations it seems likely that the sulphapyridine component of SSZ is responsible for much of the drug's toxicity. ${ }^{8}$ Therapeutic activity, on the other hand, seems to reside in the 5aminosalicylic acid (5-ASA) component of SSZ. ${ }^{-14}$

Unfortunately, 5-ASA is unstable in gastric acid and is rapidly absorbed from the small intestine. ${ }^{15}$ As

Address for correspondence: Dr S A Riley, Department of Medicine, Hope Hospital, Eccles Old Road. Salford M6 8HD.

Received for publication 16 December 1987. its mode of action is thought to be predominantly topical ${ }^{16}$ oral formulations have been developed to deliver 5-ASA to its site of action.

We have studied a delayed release form of 5-ASA (mesalazine) which relies on its coating, Eudragit $S$, to release 5-ASA in the colon. Coat dissolution is $\mathrm{pH}$ dependent occurring rapidly above $\mathrm{pH} 7$, the prevailing $\mathrm{pH}$ of the distal small intestine and colon. ${ }^{17-19}$ The aim of the present study was to compare sulphasalazine, equivalent dose mesalazine and high dose mesalazine in the treatment of mild to moderate ulcerative colitis relapse.

\section{Methods}

PATIENT SELECTION

Patients were recruited from three hospitals in close geographical proximity. The study population com- 
prised adult outpatients with mild to moderate ulcerative colitis relapse. Patients with relapse of established colitis, and those presenting as a first attack were included. All were passing blood at least once per day and all had a haemorrhagic rectal mucosa. Patients with systemic upset, usually indicating a need for treatment with corticosteroids, were excluded. No patient had received either oral or rectal steroids within two weeks of trial entry. Those taking other drugs known to have an effect on colitis activity, patients with significant hepatic or renal disease and those with a history of salicylate allergy were excluded. All patients had a negative stool culture on trial entry. The study protocol was approved by the three independent hospital ethical committees and patients gave written informed consent before study.

\section{STUDY DESIGN}

The study followed a randomised, double blind protocol. All medications were prepackaged in order to ensure an equal and random distribution to each centre. Patients were assigned to one of three treatment limbs: (a) enteric-coated SSZ $1 \mathrm{~g}$ twice daily (Salazopyrin EN, Pharmacia); (b) an equivalent dose of delayed release mesalazine, $400 \mathrm{mg}$ twice daily (Asacol, Tillotts Laboratories); or (c) a three fold larger dose of delayed release mesalazine, 1200 $\mathrm{mg}$ twice daily. As the tablets differ in shape, size, colour and dose of 5-ASA per tablet a double dummy technique was used, each patient receiving three sets of medication, two placebo and one active.

Throughout the study all clinical assessments were undertaken by one investigator. On entry to the trial a complete history and physical examination including rigid sigmoidoscopy were carried out. The macroscopic appearances of the rectal mucosa were graded on a predetermined scale (Table 1). The severity of the mucosal changes were recorded at three sites within the rectum: in the lowest $5 \mathrm{~cm}$, between 5 and $10 \mathrm{~cm}$, and above $10 \mathrm{~cm}$ with reference to the anal margin. A rectal biopsy was taken from the anterior rectal wall between 5 and $10 \mathrm{~cm}$.

Haematological (full blood count, sedimentation rate, serum and red cell folate concentrations) and biochemical variables (multichannel analysis) were measured on entry and urine samples were tested for blood and protein using a semiquantitative dip stick (Multistix, Ames).

Each patient kept a daily symptom diary in which they recorded stool frequency, bleeding, mucus, abdominal pain, possible side effects, and other symptoms they felt relevant. Patients attended for follow up at two and four weeks or at any other time should they wish. At each attendance bowel habit was recorded and corroborated with the symptom

\section{Table 1 Sigmoidoscopic and histological grading systems}

\begin{tabular}{|c|c|c|c|}
\hline \multicolumn{2}{|c|}{ Sigmoidoscopic grading } & \multicolumn{2}{|c|}{ Histological grading } \\
\hline Grade & Macroscopic appearance & Grade & Microscopic appearance \\
\hline 0 & $\begin{array}{l}\text { Normal, vascular } \\
\text { pattern clearly visible }\end{array}$ & 0 & Normal \\
\hline 1 & $\begin{array}{l}\text { Erythema with loss of } \\
\text { vascular pattern }\end{array}$ & 1 & $\begin{array}{l}\text { Mild increase in chronic } \\
\text { inflammatory cell } \\
\text { infiltrate, no tissue } \\
\text { destruction }\end{array}$ \\
\hline 2 & $\begin{array}{l}\text { As above plus contact } \\
\text { bleeding }\end{array}$ & 2 & $\begin{array}{l}\text { Moderate increase in } \\
\text { chronic inflammatory cell } \\
\text { infiltrate, no tissue } \\
\text { destruction }\end{array}$ \\
\hline 3 & $\begin{array}{l}\text { As above plus } \\
\text { spontaneous bleeding }\end{array}$ & 3 & $\begin{array}{l}\text { Marked increase in chronic } \\
\text { inflammatory cell } \\
\text { infiltrate, mild tissue } \\
\text { destruction }\end{array}$ \\
\hline 4 & $\begin{array}{l}\text { As above plus obvious } \\
\text { ulceration }\end{array}$ & 4 & $\begin{array}{l}\text { Marked increase in chronic } \\
\text { inflammatory cell } \\
\text { infiltrate, obvious tissue } \\
\text { destruction }\end{array}$ \\
\hline
\end{tabular}

diary. General well being was graded and patients were questioned as to the occurrence and frequency of a list of 15 possible side effects. Vital signs were recorded and abdominal examination done. A urine specimen was tested at each clinic visit and blood tests were repeated on completion of the study. Unused tablets were returned to assess drug compliance.

Patients were followed to either withdrawal or completion at four weeks at which time a further sigmoidoscopy and biopsy were done. Trial medications were then discontinued and oral SSZ and, if necessary, corticosteroid treatment prescribed.

On completion of the study histological analysis of the biopsy specimens was undertaken. Five micron thick paraffin embedded sections were stained with haematoxylin and eosin, coded and each examined independently by two histopathologists who had no knowledge of either the patients or treatments given. The histological changes were graded on a predetermined scale (Table 1), the final grade being the mean of the two assessments.

\section{STATISTICAL ANALYSIS}

Results are expressed as median and range unless otherwise stated. Within treatment comparisons were made using Wilcoxon's matched pairs test whereas between treatment comparisons were made using the $\chi^{2}$ or Fisher's exact test. A $5 \%$ two tailed significance level was used in each case.

\section{Results}

PATIENTS

Sixty one patients entered the study, 32 men and 29 
women, ages ranged from $20-78$ years. One patient defaulted leaving 19 in the SSZ group, 20 in the low dose mesalazine group and 21 patients in the high dose mesalazine group.

Patient and disease characteristics are shown in Table 2. The three groups were comparable with respect to age, sex, presentation as either relapse or first attack and pretrial SSZ intake. Disease extent as judged by either double contrast barium enema or the macroscopic appearances of the mucosa at colonoscopy was also similar. Disease duration was the only variable not matched as patients randomised to low dose mesalazine had a significantly longer duration of disease.

\section{RESPONSE TO TREATMENT}

On entry to the study the three groups were matched for stool frequency, rectal bleeding, sigmoidoscopic, and histological grade. Within treatment comparisons revealed significant improvement of: sigmoidoscopic grading above $5 \mathrm{~cm}$ in the SSZ group; rectal bleeding and all sigmoidoscopic grades in the low dose mesalazine group and stool frequency, rectal bleeding and all sigmoidoscopic grades in the high dose mesalazine group (Table 3). Significant improvement in histological grade occurred only in the low dose mesalazine group although significance in the high dose group approached the $5 \%$ level. Four patients, two allocated SSZ and two high dose mesalazine, suffered significant clinical deterioration and were unable to complete the four week study period.

Between treatment differences were only statistically significant when comparing the high dose mesalazine and SSZ group. On trial entry $95 \%$ of patients allocated SSZ, 85\% allocated low dose

Table 2 Patient and disease characteristics

\begin{tabular}{llll}
\hline & $\begin{array}{l}S S Z \\
n=19\end{array}$ & $\begin{array}{l}A S A(L) \\
n=20\end{array}$ & $\begin{array}{l}A S A(H) \\
n=21\end{array}$ \\
\hline Age (years) & $45(20-78)$ & $34(24-64)$ & $34(23-76)$ \\
Sex ratio & $11 \mathrm{M}: 8 \mathrm{~F}$ & $9 \mathrm{M}: 11 \mathrm{~F}$ & $12 \mathrm{M}: 9 \mathrm{~F}$ \\
Presentation & & & \\
$\quad$ First attack & 8 & 9 & 9 \\
$\quad$ Relapse & 11 & 11 & 12 \\
$\quad$ Duration (weeks) & $12(6-36)$ & $40(3-156)$ & $12(6-52)$ \\
$\quad$ First attack & $4(2-12)$ & $8(3-104)$ & $6(3-156)$ \\
$\quad$ Relapse & & & \\
Disease extent & 1 & 1 & 1 \\
$\quad$ Total & 3 & 2 & 5 \\
$\quad$ Left sided & 8 & 9 & 8 \\
$\quad$ Proctosigmoiditis & 7 & 8 & 7 \\
$\quad$ Proctitis & 7 & 7 & 8 \\
Pretrial SSZ maintenance & 7 & \\
\hline
\end{tabular}

ASA(L) - low dose mesalazine, $400 \mathrm{mg}$ twice daily; ASA(H) - high dose mesalazine, $1200 \mathrm{mg}$ twice daily; median (range).
Table 3 Response to treatment

\begin{tabular}{llcc}
\hline & $S S Z$ & $A S A(L)$ & $A S A(H)$ \\
\hline Stool frequency/day & & & \\
$\quad$ Entry & $4(2-8)$ & $3 \cdot 5(1-8)$ & $5(1-10)$ \\
$\quad$ Completion & $3(1-7)$ & $2 \cdot 5(1-7)$ & $2(1-7)^{\dagger}$ \\
Rectal bleeding/day & & & \\
Entry & $3(1-8)$ & $3(1-7)$ & $3(1-8)$ \\
$\quad$ Completion & $3(0-5)$ & $1(0-6)^{*}$ & $1(0-7)^{\dagger}$ \\
Sigmoidoscopic grade & & & \\
$0-5$ cm Entry & $3(2-3)$ & $3(2-4)$ & $3(2-3)$ \\
$\quad$ Completion & $2(1-4)$ & $2(1-4)^{\dagger}$ & $2(1-4)^{*}$ \\
5-10 cm Entry & $3(2-4)$ & $3(1-4)$ & $3(2-3)$ \\
$\quad$ Completion & $2(1-4)^{*}$ & $1(0-4)^{\dagger}$ & $2(0-4)^{*}$ \\
$>10 \mathrm{~cm}$ Entry & $3(2-4)$ & $3(1-4)$ & $2(2-3)$ \\
$\quad$ Completion & $2(1-4)^{*}$ & $1 \cdot 5(0-4)^{\dagger}$ & $1(0-4)^{*}$ \\
Histological grade & & & \\
Entry & $3(2-4)$ & $3(1-4)$ & $3(2-4)$ \\
Completion & $3(1 \cdot 5-4)$ & $2(0-3)^{*}$ & $2 \cdot 5(1-4)$ \\
\hline
\end{tabular}

Median (range); within treatment significance: ${ }^{*} \mathrm{p}<0 \cdot 005 ; \mathrm{\dagger}<0 \cdot 01$.

mesalazine and $95 \%$ allocated high dose mesalazine were passing three or more stools per day. On completion of the study the percentages had fallen to $47 \%, 30 \%$, and $19 \%$ respectively $(\mathrm{p}<0.1$ high dose mesalazine versus SSZ).

All patients were passing blood at least once daily on entry to the study. Improvement in rectal bleeding occurred in $47 \%$ taking SSZ, $75 \%$ taking low dose, and $81 \%$ taking high dose mesalazine $(p<0.05$ high dose mesalazine versus SSZ). Symptomatic remission (resolution of rectal bleeding and three or less stools per day) was seen in $21 \%, 30 \%$, and $43 \%$ of the groups respectively $(p<0 \cdot 2)$.

All patients included in the study had sigmoidoscopic evidence of active disease (grade 2 or more, Table 1). After four weeks' treatment significant improvement (grade 1 or less) was seen in $5 \%$ of patients receiving SSZ, $25 \%$ receiving low dose and $33 \%$ high dose mesalazine $(\mathrm{p}<0.05$ high dose mesalazine versus SSZ). No significance between treatment differences was apparent with respect to histological grade.

Pretrial SSZ intake appeared to be a major predictor of treatment outcome. Of the 23 patients taking SSZ at trial entry, only 13 patients improved and only two achieved symptomatic remission during the four week trial. In the group of 37 patients not taking SSZ at trial entry, however, 31 patients improved and 17 achieved symptomatic remission $(p<0.005)$. The influence of pretrial SSZ intake on treatment outcome by treatment group is shown in Table 4.

SIDE EFFECTS AND LABORATORY VALUES

Two patients were unable to complete the study because of drug related side effects. One patient 
Table 4 The influence of pretrial SSZ intake on treatment outcome

\begin{tabular}{llllllll}
\hline & \multicolumn{3}{c}{$S S Z$} & \multicolumn{1}{c}{$A S A(L)$} & \multicolumn{2}{c}{$A S A(H)$} \\
\hline Pretrial SSZ intake & + & - & + & - & + & - \\
Patients/group & 7 & 12 & 7 & 13 & 9 & 12 \\
Number improved (\%) & $1(14)$ & $9(75)$ & $5(71)$ & $11(84)$ & $7(77)$ & $11(92)$ \\
Number achieving & $0(0)$ & $4(33)$ & $2(28)$ & $4(31)$ & $0(0)$ & $9(75)$ \\
$\quad$ symptomatic & & & & & & \\
$\quad$ remission (\%) & & & & & & \\
\hline
\end{tabular}

developed an itchy morbilliform rash five days after entering the trial, the other developed intractable heartburn and vomiting. Both patients had been allocated SSZ and now tolerate mesalazine well.

Headaches and gastrointestinal symptoms (anorexia, nausea, vomiting, and dyspepsia) were the side effects tolerated the most. During the trial regular headaches were reported by six patients taking SSZ, four taking low dose mesalazine and five high dose mesalazine and regular upper gastrointestinal upset reported by four, four, and seven patients respectively.

On entry to the study all laboratory variables were closely matched in the three treatment groups. After four weeks treatment a small but significant fall in mean haemoglobin concentration was apparent in the SSZ treated group (entry $13.5(1.3) \mathrm{g} \mathrm{\%}$, completion $13.0(1.3) \mathrm{g} \%$, mean (SD), $\mathrm{p}<0.05)$. No such change was seen in either of the groups treated with mesalazine. Other haematological indices were unchanged throughout the study period although one patient receiving SSZ developed a mild leucopenia which resolved spontaneously.

Mean plasma urea and creatinine concentrations in the three groups showed no significant changes throughout the study period. Two patients allocated high dose mesalazine, however, had developed minor rises in plasma creatinine concentrations (up to two fold) on completion of the study. Neither patient had abnormalities on urine testing and both resolved spontaneously. No other significant biochemical abnormalities were apparent.

\section{Discussion}

The results of this study show that delayed release mesalazine is a useful drug in patients with active ulcerative colitis. In equivalent dose the drug was as effective, and at high dose more effective than SSZ in the treatment of mild to moderate ulcerative colitis relapse. Differences between the high dose and low dose treatment groups, however, were not statistically significant.

After four weeks treatment improvement had occurred in nine of $19(47 \%)$ patients receiving SSZ,
15 of $20(75 \%)$ receiving low dose, and 17 of $21(81 \%)$ high dose mesalazine. Symptomatic remission had occurred in four of 19 , six of 20 , and nine of 21 patients respectively. The effects of high dose mesalazine were particularly impressive in the subgroup not taking maintenance SSZ therapy at trial onset. In this group 11 of the 12 improved, nine achieved symptomatic remission and six achieved sigmoidoscopic remission.

Several previous studies have assessed the value of oral SSZ in mild to moderate ulcerative colitis relapse. Although SSZ dose and trial designs have varied considerably clinical improvement has been reported in $65 \%$ to $80 \%$ and symptomatic remission in 25 to $52 \%$ of the groups studied. ${ }^{+62021}$ As these studies were undertaken in patients not receiving SSZ maintenance treatment, the results of high dose mesalazine treatment in a similar group in the present study are particularly encouraging.

The main drawback of SSZ therapy is the drug's toxicity and in the present study two patients were withdrawn because of side effects. Neither patient had been taking SSZ maintenance therapy before trial entry. No patient who received mesalazine treatment had to be withdrawn. Headaches and upper gastrointestinal upset, however, were equally matched in the three groups and other side effects were too infrequent to assess.

No major differences in haematological indices developed in the three treatment groups during the trial period although a small fall in haemoglobin concentration was apparent after SSZ treatment. Although possibly a drug related change, there was no evidence of haemolysis, reticulocytosis or macrocytosis. The fall probably reflects continuing disease activity and blood loss in the group who responded least well to treatment.

5-aminosalicylic acid has structural similarities to phenacetin and salicylic acid and both these agents have been incriminated in analgesic nephropathy. ${ }^{22}$ In addition, studies in the rat have shown that large intravenous doses of 5-ASA can cause renal tubular and renal papillary necrosis. ${ }^{232}$ In the present study, two patients developed raised creatinine concentrations after four weeks' treatment with high dose mesalazine. Both cases were asymptomatic, neither had abnormalities on urine testing and both resolved spontaneously on changing to SSZ maintenance treatment at the end of the trial. Only one other case of nephrotoxicity has appeared in the literature..$^{25}$ In another clinical trial, however, high dose mesalazine was found to be safe and effective over a period of 24 weeks. ${ }^{26}$ In the only detailed study of renal function Diener $e t a^{27}$ could find no evidence of nephrotoxicity in patients with Crohn's disease taking $1.5 \mathrm{~g}$ daily of a slow release 5-ASA preparation. No other 
cases of renal impairment have been reported to the manufacturers, Tillotts Laboratories, although information on patients taking high dose mesalazine is still limited (personal communication). Further studies are clearly indicated and at present renal function should be closely monitored in patients taking high dose mesalazine.

Oral 5-ASA formulations not only offer the hope of improved toxicity compared with SSZ but also the possibility of greater therapeutic effect by the use of larger doses. The main advantage of delayed release mesalazine, to date, is its improved toxicity. Studies in patients unable to take SSZ because of allergic reactions or side effects have shown that the majority of patients tolerate mesalazine well although a small number do report side effects similar to those seen with SSZ. ${ }^{28}{ }^{29}$ In addition, SSZ-induced male infertility and seminal impairment respond favourably to mesalazine substitution. ${ }^{31}$ The drug is as effective as an equivalent dose of SSZ in the longterm maintenance of ulcerative colitis remission ${ }^{3132}$ but unfortunately high dose studies have, as yet, failed to realise additional benefit. ${ }^{26}$ Previous studies in active colitis are limited to an open uncontrolled trial of high dose mesalazine in which $67 \%$ improvement was reported after one month of treatment. ${ }^{25}$

The present study shows that delayed release mesalazine in equivalent dose is as effective and in high dose appears more effective than SSZ in the treatment of mild to moderate ulcerative colitis relapse. Clinical side effects were no more common in patients treated with high dose mesalazine. In two patients raised creatinine concentrations occurred however, and this suggests the need for further toxicity studies.

The authors wish to thank the staff of the Department of Pathology, Bury General Hospital for processing the biopsy materials; Alison Littlewood, Staff Pharmacist, Hope Hospital for coding and packaging trial drugs; and Joan Hartley and Julie Rostron for their secretarial help. Financial support for this study was provided by Tillotts Laboratories, UK. The results of this study have been presented to the British Society of Gastroenterology, September 1987.

\section{References}

1 Misiewicz JJ, Lennard-Jones JE, Connell AM, Parson $\mathrm{JH}$, Avery-Jones F. Controlled trial of sulphasalazine in maintenance therapy for ulcerative colitis. Lancet 1965 ; i: $185-8$.

2 Dissanayake AS, Truelove SC. A controlled therapeutic trial of long-term maintenance treatment of ulcerative colitis with sulphasalazine (Salazopyrin). Gut 1973; 14: 923-6.
3 Azad Khan AK, Howes DT, Piris J, Truelove SC. Optimum dose of sulphasalazine for maintenance treatment of ulcerative colitis. Gut 1980; 21: 232-40.

4 Lennard-Jones JE, Longmore AJ, Newell AC, Wilson CWE, Avery Jones F. An assessment of prednisolone, salazopyrine and topical hydrocortisone hemisuccinate used as outpatient treatment for ulcerative colitis. Gut 1960; 1: 217-22.

5 Baron JH, Connell AM, Lennard-Jones JE, AveryJones FA. Sulphasalazine and salicylazosulphadimidine in ulcerative colitis. Lancet 1962; i: 1094-6.

6 Dick AP, Grayson MJ, Carpenter RG, Petrie A. Controlled trial of sulphasalazine in the treatment of ulcerative colitis. Gut 1964; 5: 437-42.

7 Taffet SL, Das KM. Sulfasalazine. Adverse effects and desensitization. Dig Dis Sci 1983; 28: 833-42.

8 Das KM, Eastwood MA, McManus JPA, Sircus W. Adverse reactions during salicylazosulphapyridine therapy and the relation with drug metabolism and acetylator phenotype. N Engl J Med 1973; 289: 491-5.

9 Azad Khan AK, Piris J, Truelove SC. An experiment to determine the active therapeutic moiety of sulphasalazine. Lancet 1977; ii: 892-5.

10 Van Hees PAM, Bakker JH, van Tongeren JHM. Effect of sulphapyridine, 5-aminosalicylic acid, and placebo in patients with idiopathic proctitis: a study to determine the active therapeutic moiety of sulphasalazine. Gut 1980; 21 : 632-5.

11 Klotz U, Maier K, Fischer C, Heinkel K. Therapeutic efficacy of sulphasalazine and its metabolites in patients with ulcerative colitis and Crohn's disease. N Engl J Med 1980; 303: 1499-502.

12 Campieri N, Lanfranchi GA, Bazzochi G, et al. Treatment of ulcerative colitis with high-dose 5aminosalicyclic acid enemas. Lancet 1981; ii: 270-1.

13 Campieri N, Lanfranchi G, Brignola C, Bazzocchi G, Minguzzi M, Calari M. 5-aminosalicylic acid as rectal enema in ulcerative colitis patients unable to take sulphasalazine. Lancet 1984; i: 403.

14 Sutherland LR, Martin F, Greer S, et al. 5aminosalicylic acid enema in the treatment of distal ulcerative colitis, proctosigmoiditis and proctitis. Gastroenterology 1987; 92: 1894-8.

15 Nielson $\mathrm{OH}$, Bondesen S. Kinetics of 5-aminosalicylic acid after jejunal instillation in man. $B r J$ Clin Pharmacol 1983; 16: 738-40.

16 Campieri M, Lanfranchi GA, Boschi S, et al. Topical administration of 5-aminosalicylic acid enemas in patients with ulcerative colitis. Studies on rectal absorption and excretion. Gut 1985; 26: 400-5.

17 Lehmann K. Programmed drug release from oral dosage forms. Pharmacol Int 1971; 3: 1-16.

18 Bown RL, Gibson JA, Sladen GE, Hicks B, Dawson AM. Effects of lactulose and other laxatives on ileal and colonic $\mathrm{pH}$ as measured by a radiotelemetry device. Gut 1974; 15: 999-1004.

19 Dew MJ, Hughes PJ, Lee MG, Evans BK, Rhodes J. An oral preparation to release drugs in the human colon. Br J Clin Pharmacol 1982; 14: 405-8.

20 Truelove SC, Watkins G, Draper G. Comparison of corticosteroid and sulphasalazine therapy in ulcerative colitis. Br Med J 1962; ii: 1708-11. 
21 Watkinson G. Medical management of ulcerative colitis. Br Med J 1961; i: 147-9.

22 Calder IC, Funder CC, Green CR, Ham KN, Tange JD. The comparative nephrotoxicity of aspirin and phenacetin derivatives. $\mathrm{Br}$ Med J 1971; iv: 518-21.

23 Calder IC, Funder CC, Green CR, Ham KN, Tange JD. Nephrotoxic lesions from 5-aminosalicylic acid. Br Med J 1972; i: 152-4.

24 Briggs D, Calder IC, Woods R, Tange JD. The influence of metabolic variation on analgesic nephrotoxicity. Experiments with the Gunn rat. Pathology 1982; 14: 349-53.

25 Schroeder KW, Tremaine WJ. Oral 5-aminosalicylic acid (Asacol) for treatment of symptomatic chronic ulcerative colitis. Gastroenterology 1986; 90: 1620.

26 Dew MJ, Harries AD, Evans N, Evans BK, Rhodes J. Maintenance of remission in ulcerative colitis with 5amino salicylic acid in high doses by mouth. Br Med J 1983; 287: 23-4.

27 Diener V, Turzek HV, Fischer C, Maier K, Klotz U. Renal function was not impaired by treatment with 5- aminosalicylic acid in rats and man. Arch Pharmacol 1984; 326: 278-82.

28 Donald IP, Wilkins SP. The value of 5-aminosalicylic acid in inflammatory bowel disease for patients intolerant or allergic to sulphasalazine. Postgrad Med J 1985; 61: 1047-8.

29 Dew MJ, Harries AD, Evans BK, Rhodes J. Treatment of ulcerative colitis with oral 5-aminosalicylic acid in patients unable to take sulphasalazine. Lancet 1983; ii: 801.

30 Riley SA, Le Carpentier J, Mani V, Goodman MJ, Mandal BK, Turnberg LA. Sulphasalazine-induced seminal abnormalities in ulcerative colitis: results of mesalazine substitution. Gut 1987; 28: 1008-12.

31 Dew MJ, Hughes P, Harries AD, Williams G, Evans BK, Rhodes J. Maintenance of remission in ulcerative colitis with oral preparation of 5-aminosalicylic acid. Br Med J 1982; 285: 1012.

32 Riley SA, Mani V, Goodman MJ, Turnberg LA. A comparison of delayed-release 5-aminosalicylic acid and sulphasalazine as maintenance treatment of ulcerative colitis. Gastroenterology 1987; 92: 1596. 